\title{
浅析建筑工程中深基坑支护施工技术的应用
}

\author{
郝 军* \\ 陕西秦川建设工程有限公司, 陕西 714000
}

\begin{abstract}
摘 要: 企业在进行建筑工程建设的过程中, 所应用的深基坑支护技术会直接影响到工程的总体建设质量和安 全。如果企业没有选用正确的深基坑技术, 就会降低工程的总体建设效果。而且企业在进行技术应用时, 如果没有根 据工程的建设要求, 对技术的应用形式进行科学的改进, 就会导致技术的应用效果不断降低。因此施工企业一定要认 识到深基坑支护施工技术应用的重要性, 并且提高这个环节的建设质量。在进行工程建设时, 还要对技术的应用重点 和难点进行准确的把握, 才能进一步提高工程的总体建设质量。本文就建筑工程中深基坑支护施工技术的应用进行相 关的分析和探讨。
\end{abstract}

关键词：建筑工程；深基坑支护施工技术；应用；分析探讨

\section{Analysis on the Application of Deep Foundation Pit Support Construction Technology in Construction Engineering}

\author{
Jun Hao* \\ Shaanxi Qinchuan Construction Engineering Co., Ltd., Weinan 714000, Shaanxi, China
}

\begin{abstract}
The deep foundation pit support technology applied by an enterprise in the course of project construction will directly affect the overall construction quality and safety of the project. If the company does not select the correct deep foundation pit technology, the overall construction effect of the project will be reduced. In addition, in the application of technology, if the company does not make scientific improvements to the application form of the technology according to the construction requirements of the project, the application effect of the technology will continue to decrease. Therefore, construction enterprises must recognize the importance of the application of deep foundation pit support construction technology and improve the quality of construction in this link. In order to further improve the overall construction quality of the project, it is necessary to grasp the key points and difficulties of technology application accurately. This paper analyzes and discusses the application of deep foundation pit support construction technology in construction engineering.
\end{abstract}

Keywords: Construction engineering; deep foundation pit support construction technology; application; analysis and discussion

\section{一、前言}

近几年建筑行业的发展非常的迅速, 在进行工程项目建设的过程中, 深基坑支护技术的应用重要性也在不断地提 高。但是很多施工企业在进行这个项目建设的过程中, 并没有认识到技术应用的重要性, 也没有根据工程的建设要求 以及实际施工情况选用正确的施工技术, 这就导致这个项目的建设质量和建设安全正在不断的降低。实际上在进行工 程项目建设的过程中, 深基坑支护属于临时性的支护项目，可以保证工程项目的建设安全。如果施工企业没有对这个 环节进行重点关注, 也没有采用更加先进的支护技术, 就会影响工程项目的建设进程, 也会给施工企业带来额外的经 济损失 ${ }^{[1]}$ 。

\section{二、建筑工程中深基坑支护施工技术的应用特点 \\ (一) 地域性特点比较强}

*通讯作者: 郝军, 1978年5月, 男, 汉族, 陕西延安人, 现任陕西秦川建设工程有限公司项目经理, 工程师, 大 专。研究方向: 房屋建筑工程。 
因为我国的地域比较广阔, 我国的东部和西部区域以及北部和南部区域的地理情况存在较大的差异, 土壤结构也 有所不同。

如图1所示, 在进行实际支护作业的过程中, 支护形式的应用存在明显的区域性差别。施工企业在进行建筑工程 建设的过程中, 要对深基坑支护能力和建设用地形势进行深人的了解和研究, 还要明确施工技术运用的重要性。并且 根据不同建设区域的土壤条件和工程的建设要求，选用合理的施工技术，才能这一项目的施工能够顺利进行。

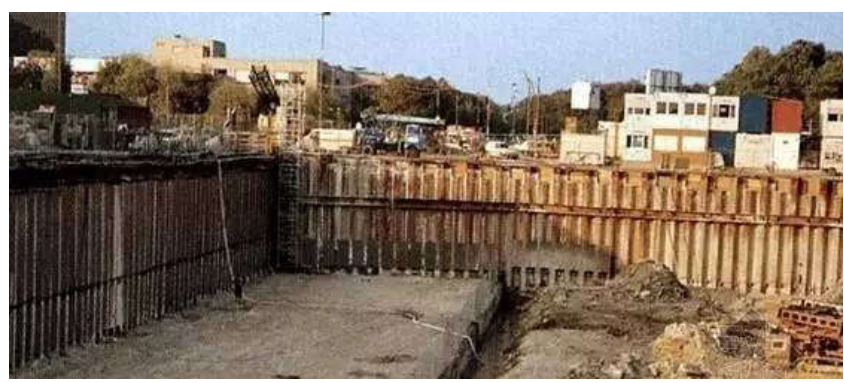

图1 支护作业

施工企业必须对技术的应用形式进行准确的把握，而且在进行具体建设的过程中，还要根据区域内的特点对技术进 行改善和优化，才能进一步发挥技术的应用效果，确保深基坑的支护更加稳定，为工程项目的建设提供有效的支持 ${ }^{[2]}$ 。

（二）施工情况更加复杂

如图2所示，一般来说在进行工程项目建设的过程中，为了提高作业的安全性，技术人员要对深基坑支护作业环 节进行重点关注。在进行支护作业的施工前期, 要对建设区域内的土质情况进行准确的测量和科学的计算。在开展这 些工作的过程中, 因为不能对所有的土质进行全面的测量, 这就导致测量结果在应用的过程中存在一定的片面性, 会 影响后续支护作业的施工安全。

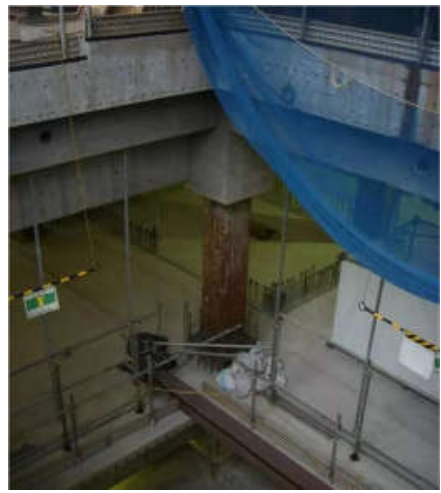

图2 工程建设

目前在进行土质测量的过程中一般存在两种方法, 主要是库伦土压测量方法和郎肯土压测量方法。这两种方法在 应用的过程中具备较高的科学理论依据, 但是在进行实际操作的过程中存在较多的限制, 都是在理论的假设中进行具 体操作的。因此在开展实际测量工作的过程中, 得出的具体结果与计算数据存在较大的差异。所以施工企业在开展这 些工作的过程中, 必须提高最终测量结果的准确性，才能保证深基坑支护作业在操作的过程中更加的安全。施工企业 也要对这项技术应用的复杂性特点进行深入的了解 ${ }^{[3]}$ 。

（三）施工阶段容易发生安全事故问题

在进行深基坑支护施工的过程中，周边的土质联系比较强，会对工程的具体建设产生较大的影响。会威胁建设的 安全与稳定, 导致施工人员面临较多的风险问题, 而且容易引发一些安全事故。特别是在进行一些项目建设的过程 中, 因为支护工作不到位, 受到外界较多的影响, 导致支护结构无法发挥应有的作用, 严重威胁了建筑物的应用安 全，导致安全事故频频发生。在这个过程中不仅会延缓工程项目的建设进度，甚至会造成施工人员的伤亡问题，会给 施工企业带来额外的经济损失, 导致项目的建设存在更多的冲突和纠纷问题。因此施工企业必须对施工阶段进行重点 管理, 要对每项技术的应用效果进行科学的比较, 才能选用正确的施工技术进行具体的建设, 从而保证施工阶段的建 
设更加的稳定，降低事故问题的发生概率。因此施工企业一定要做好现场的安全防护，才能提高作业的安全性 ${ }^{[4]}$ 。

( 四) 现有的支护类型比较多

现阶段在进行工程项目深基坑作业的过程中, 技术的应用类型比较多, 所面临的支护类型也比较多。虽然各项技 术的发展已经比较成熟, 也研发出来了更多的施工技术, 但是在进行具体应用的过程中, 这些技术的运用效果还不是 非常的完美。要通过技术组合的形式进行具体的操作, 这种组合形式可以满足复杂结构的支护要求, 而且能够进一步 提高作业的效果。在应用这些技术的过程中, 还可以保证支护的稳定性和安全性。因此施工企业必须根据工程项目的 具体要求, 选用具体的支护类型, 并且促进项目的顺利建设完成 ${ }^{[5]}$ 。

\section{三、建筑工程中深基坑支护施工技术的具体应用}

在我国建筑行业不断发展的过程中, 施工技术的应用正在探索和实践阶段, 其中的深基坑支护施工技术已经取得 了一定的成果，而且在应用的过程中建立了比较完善的应用体系。所以在应用相关技术时，技术的发展更加的成熟， 可以满足不同类型的施工要求。目前我国在进行建筑工程项目建设的过程中, 常用的工程施工技术, 有以下几种形 式。在进行这些施工技术应用的过程中, 具有不同的特点, 也能发挥出不同的效果, 所以在进行项目建设过程中, 一 定要根据作业要求选择技术类型, 从而促进工程建设的顺利开展 ${ }^{[6]}$ 。

(一) 土钉支护施工形式

在应用这项技术的过程中，主要是对基坑的边缘进行加固。施工企业在应用这项技术时，可以充分利用土钉之间 所产生的一种作用力来实现加固功能。而且这种施工技术在应用的过程中具有较多的优势, 其中一项最主要的优势, 可以保障基坑土体结构的整体性, 确保机构在应用的过程中更加的安全稳定。在对工程项目的地下室结构进行施工的 过程中, 土体结构会在拉力和弯矩的影响下出现变形等情况。施工企业在进行这个环节建设的过程中, 需要严格按照 工程的施工标准, 对土钉的建设强度和抗拉力进行科学的规划和设计, 确保这项技术在应用的过程中, 能够满足工程 施工的各项要求 ${ }^{[7]}$ 。

在应用这项技术的过程中, 施工企业要对一些作业环节进行重点关注。在进行标准的土钉拉拔实验时, 要对拉拉 力进行明确的规定。在开展相关试验时, 必须对工程项目建设的参与方进行具体的查验, 要保证这些建设单位都能参 与到实验的开展过程中。在开展具体实验的过程中, 还要对注浆的用量和作业的力度进行严格的控制。在进行具体作 业的过程中, 要按照钻机的总长度对钻孔的深度进行具体的计算, 每一个孔口的深度都要明确地标注出来。在进行工 程建设的过程中, 要根据施工的具体要求, 对材料的配比和添加剂的类型以及用量进行全面的控制, 才能保证这一项 目的建设更加顺利。在完成注浆作业之后，应该在初凝之前进行补浆作业。

施工企业在进行这项施工技术应用的过程中，应该根据工程项目的具体要求以及施工作业的主要形式，对技术的 应用效果进行全面的把控, 才能保证技术在应用的过程中能够发挥更大的作用, 促进各个环节的顺利进行。避免因为 在进行技术应用的过程中, 某一环节出现了问题，影响下一作业程序的开展 ${ }^{[8]}$ 。

(二) 土层针杆支护施工形式

如图3所示, 在进行这一施工技术应用的过程中, 主要的作业流程, 要根据具体计划的要求, 对施工技术进行具 体的选择。

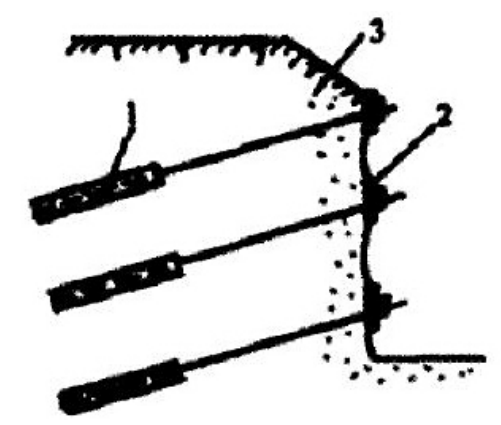

图3 土层针杆施工技术

1. 在开展测量工作时

工作人员要对建筑工地的针和轴承以及工具进行全面的了解，要对各项情况进行检查和改正。 


\section{2. 在进行具体作业的过程中}

施工人员必须严格按照规章制度的要求，对钻井深度的作业情况进行科学的规划和操作。

3. 在使用针的过程中

要对针的各项情况进行全面的检查, 尤其是在对深基坑进行建设的过程中, 要对总体视图进行全面的了解, 并且 对每项作业的开展情况进行详细的记录。

4. 在作业的过程中

如果发现存在任何异常情况, 或者在施工阶段遭受了阻碍, 就要立即停止作业, 要对这些问题的影响程度进行全 面的分析，并且对导致这些问题出现的原因进行查找，才能制定科学有效的措施解决这些问题 ${ }^{[0]}$ 。

5. 在进行技术应用的过程中

施工企业还要根据相关环节的施工要求，对螺栓和水平孔的作业距离进行严格的控制，要将误差控制在允许的范 围内。

6. 在对底部进行钻孔作业时

作业的规模也应该控制在标准的范围内。如果在深基坑作业的过程中，相关材料的规格和质量不符合作业的要 求, 那么施工企业就要对这些问题进行及时的查找, 并且根据作业要求对这些材料进行及时的更换, 才能保证作业的 开展顺利，避免在作业时存在一些杂物。施工人员还要对材料进行均匀的拌和，才能保证这一环节的作业质量 ${ }^{[10]}$ 。

(三) 排桩支护施工形式

在进行支护作业的过程中，这项技术的应用特点就是操作的灵活性更高，而且使用的范围更广。当前在进行建筑 工程项目建设的过程中，建设规模正在不断地扩大，建设数量也在不断的增多。在进行深基坑作业的过程中，建设程 度也在不断的加深。如果在进行工程项目建设的过程中, 使用了一些软土材料, 要想对深基坑进行有效的支护, 就要 提高支护桩和注浆防水的效果, 更要对实际建设区域的土壤进行科学的安排。如果建设场地的地下水位比较低, 可以 采用挖掘挖桩的作业形式。在进行具体作业的过程中, 要将桩基组成数量按照科学的配比进行具体的安排。如果建设 区域的地下水位比较高, 可以采用水泥摚拌桩的作业形式, 这种作业形式不仅防水效果比较好, 而且可以阻止土壤的 变形。

当然施工企业在进行具体建设的过程中，要根据深基坑的作业深度来选用正确的钻孔桩。在进行作业时，如果实 际作业的深度比较深, 那么钻孔桩的设置密度就要更大。要保证深基坑的作业深度和钻孔密度出现重比的联系。在进 行深基坑作业的过程中, 还要保证钢板桩的支撑结构和地下连续桩的支持能力更强。与此同时施工企业还要选用钢板 墙进行土壤的固定和屏蔽，因为这种作业形式的效率更高，在使用的过程中可以作用于建设深度为 8 米的深基坑作业 过程中，如果区域内的软土土质比较多，可以使用这种技术，这种技术的利用率比较高。

但是施工企业要注意，在进行这种施工技术应用的过程中，可能存在比较大的施工噪音。而且在进行实际建设 时, 投人的人力物力资源都比较多, 在施工的后期要进行大规模的处理作业。所以这项技术的应用范围比较窄, 施工 企业必须根据工程项目的具体要求, 对技术的应用形式进行具体的选择, 才能保证这个项目能够顺利的建设完成, 并 且降低施工的成本。

\section{四、结语}

综上所述, 施工企业在进行工程的基础项目建设时, 应该认识到深基坑支护施工的重要性。施工企业要选用正确 的支护施工技术，才能提高工程的建设质量，同时进一步提高技术工程的施工水平。施工企业必须对现有的深基坑 支护施工技术进行深人的了解, 还要对技术应用过程中的各项要求进行准确的把握, 才能充分发挥这项技术的应用效 果，确保工程项目能够顺利的建设完成。施工企业也要加强技术的研发，在现有的技术基础上改善技术的应用形式， 确保技术在应用的过程中能够发挥更大的作用，从而促进工程项目进行可持续的发展。

\section{参考文献:}

[1]张伟玉,杨志荣,王薇.深基坑支护结构和新施工工艺在某高层建筑工程中的应用[J].施工技术, 2015,44(S1):10-13.

[2]薛剑茹,杨得志.深基坑支护施工技术在建筑工程中的应用分析[J].科技创新与应用, 2016(07):268.

[3]孙志群,肖先炳.刍议深基坑支护施工技术在建筑工程中的应用 [J].中国高新技术企业, 2016(31):94-95.

[4] 郝艳领,王刚,王庆辉.深基坑支护施工技术在建筑工程中的应用分析 [J].门窗, 2014(01):89+92. 
[5]谢国樑,陈鹏程.深基坑支护施工技术在建筑工程中的应用分析[J].建材与装饰, 2019(04):32-33.

[6]廖国骄,谭文琦.深基坑支护施工技术在建筑工程中的应用 [J].江西建材, 2019(04):122+124.

[7]潘学刚,王梦琴,李琛.建筑工程中的深基坑支护施工技术分析[J].建材与装饰, 2019(26):19-20.

[8]曹歌,颜珩,张呱.深基坑支护施工技术在建筑工程中的应用[J].中国新技术新产品, 2017(21):101-102.

[9]周保军,杜晓玉.深基坑支护施工技术在建筑工程中的应用分析[J].建材与装饰, 2018(33):5.

[10]努尔妮萨罙 - 阿卜杜拉.深基坑支护施工技术在建筑工程中的应用分析 [J].住宅与房地产, 2018(25): 194 . 